Anuario de la Facultad de Derecho. Universidad de Extremadura 36 (2020): 673-693 ISSN: 0213-988X - ISSN-e: 2695-7728

Doi: https://doi.org/10.17398/2695-7728.36.673

\title{
CRIMINOLOGÍA Y GLOBALIZACION
}

\author{
CRIMINOLOGY AND GLOBALIZATION
}

José ANTONIO MICHILINI

Universidad de Buenos Aires. Argentina

Nicolás Pablo SEgura

Universidad de Buenos Aires. Argentina

Recibido: 28/10/2020 Aceptado: 18/12/2020

\section{RESUMEN}

En las líneas que siguen intentaremos realizar un abordaje vinculado a los distintos enfoques que la criminología contemporánea le ha dado al estudio del delito, del delincuente, de la víctima y del control social del comportamiento delictivo. Ello se debe a que, sin lugar a duda, el debate epistemológico que rodea esta disciplina ha ido mutando con el paso del tiempo y el impacto que el fenómeno de la globalización ha causado, ha tenido que ver con eso.

Palabras clave: Criminología, crítica, globalización.

\section{ABSTRACT}

In the following lines we will try to make an approach related to the different points of views that contemporary criminology has given to the study of crime, the offender, the victim, and the social control of criminal behaviour. This finds correlation with the fact that, with no doubt, the epistemological debate that surrounds this discipline has been 
changing throught time and the impact that the phenomenon of globalization produced, has to do with it.

Keywords: Criminology, critic, globalization.

Sumario: Introducción. 1.1. El impacto de la globalización en la criminología. El debate epistemológico. 1.2. El rol de la criminología contemporánea y el aporte de la obra -traducida- de Wayne Morrison. 2. El “apartheid gnoseológico”. 2.1. La repercusión de la globalización. El daño social. 3. La criminología crítica. 3.1. Una aproximación a la criminología global. 4. El escepticismo criminológico. 5. Palabras finales.

\section{INTRODUCCIÓN}

En esa línea, podría decirse en primer lugar que, si bien la criminología ha ido evolucionando en sus métodos de investigación y en el abordaje de las distintas cuestiones que abarcan su campo de estudio, lo cierto es que han sido algunos acontecimientos mundiales los que han provocado las rupturas epistemológicas más simbólicas.

Como es sabido, esta disciplina siempre ha encarado sus investigaciones considerando, entre otros tantos factores, las causas, las consecuencias y la repercusión que eventos de tal magnitud, tales como las guerras mundiales, las crisis económicas y los avances científicos, han causado en las distintas realidades sociales de la comunidad internacional.

Por ello, el abordaje que aquí habremos de realizar pretende centrarse en el impacto que la globalización pudo haber tenido a nivel global -en términos de delincuencia- y cómo la criminología ha venido intentando hacerle frente a este fenómeno.

Para empezar, podría recordarse entonces lo sostenido por Marshall MacLuhan en la década del 60', quien, tenía dicho que, como consecuencia de la evolución material de los medios de comunicación y de las nuevas tecnologías de información, la humanidad había ingresado en otra etapa evolutiva, a la que denominaba "La aldea global". 
Allí, expresaba:

“...El cambio constante, y sin razón alguna, amenaza a todos. (Una de las cosas interesantes sobre la tecnología en constante mutación es que representa una de las principales fuentes de inflación.). En un estado de implosión social, inducida por la información que se mueve a la velocidad de la luz, aquellos que forman parte de monopolios de la información... no verán el cambio como algo amenazador. Pero cuando las personas corrientes no saben quiénes son, se tornan ansiosas y violentas."

Algo de todo eso que MacLuhan explicaba hace unas décadas, se refleja en forma clara en la actualidad, pues la interacción virtual hace que podamos comunicarnos con otra persona, de una punta a la otra del planeta en forma instantánea, para bien y para mal, con fines constructivos y destructivos.

El escenario mundial actual, en el que la información circula de manera vertiginosa, atraviesa entonces casi sin reparos las fronteras culturales, sociales, políticas y económicas de los países, dando lugar a una globalización tecnocrática y mercantilista que no detiene su avance ante nada.

En palabras de Zygmun Baumann la globalización expresa la idea del carácter indeterminado, ingobernable y autopropulsado de los asuntos mundiales. En resumidas palabras, la globalización para Baumann es el "nuevo desorden mundial"2.

En términos criminológicos, podría afirmarse entonces que el crimen se ha globalizado y la respuesta que produce también, pues la comunidad internacional ha visto la necesidad de intervenir cuanto antes en aquella problemática. Tal circunstancia, ha llevado a la criminología a adecuarse a los nuevos tiempos, debiendo retomar aquellos principios de la criminología crítica y profundizarlos,

1 Marshall MacLuhan y B. R. Powells, “La Aldea Global”. Transformaciones en la vida y los medios de comunicación mundiales en el siglo XXI en la Colección "El Mamífero Parlante" dir. por Eliseo Verón, (Barcelona: Edit. Gedisa, tercera edición, 1995), 104.

2 Zygmun Baumann "La globalización. Consecuencias humanas", (Buenos Aires: Fondo de cultura económica, 1999), 80. 
pero desde una perspectiva más global y moderna, que facilite un estudio más completo y acabado de la realidad actual.

En esa línea, aparece como relevante la obra de Wayne Morrison denominada "Criminología, civilización y nuevo orden mundial", en donde el autor se pregunta ¿Qué rol cumplió la criminología mientras se perpetraron las grandes masacres de mediados del S.XIX a la actualidad? y si ¿podrá una nueva criminología crítica global hacer frente al estudio de semejantes atrocidades?3.

Tales cuestionamientos, nos llevan inevitablemente a preguntarnos por qué la criminología pasó por alto el estudio crítico de tan cruentos fenómenos mundiales. De aquellos oscuros momentos y hasta la actualidad, el devenir de la historia ha provocado que la criminología fuera mutando y transformándose en algo más que en la disciplina que focalizaba sus esfuerzos en el estudio de las personas y sus comportamientos.

En esa dirección, como bien señala Luis Fernando Tocora López:

“...Esto ya dibuja una tendencia hacia leyes globales y jurisdicciones supranacionales. A este último respecto se ha puesto en marcha hace relativamente poco tiempo (1998) la Corte Penal Internacional (C.P.I.) creada por el Estatuto de Roma, con una competencia complementaria para conocer y juzgar genocidios, delitos de guerra y de lesa humanidad... Esta coordenada internacional empieza a imponer... por la vía de convenciones o pactos internacionales desde los cuales se recomienda a los Estados parte crear legislaciones penales dentro de los parámetros ventilados y propuestos en dichos encuentros internacionales..."4.

Es decir que, poco a poco, aunque sin dejar de lado el estudio del individuo y sus comportamientos, el objeto de estudio de la criminología fue expandiéndose para abordar distintos fenómenos que comenzaron a originarse -gracias a los avances tecnológicos tales como la informática, las imágenes, los datos y las

3 Wayne Morrison “Criminología, civilización y nuevo orden mundial”, traducida y editada por Camilo Bernal Sarmiento, Sebastián Cabezas Chamorro, Alejandro Forero Cuellar, Iñaki Rivera Beiras, Iván Vidal Tamayo y Fidel Amat, (Barcelona: Edit. Anthropos, 2012), 53.

4 Luis Fernando Tocora López "Política criminal global en América Latina. Mitos y realidades", (Buenos Aires: Edit. Eudeba, 2015), 22. 
comunicaciones, entre otros tantos- y a visualizarse a partir de la globalización, como ser el crimen internacional en todas sus dimensiones, más organizado y perjudicial para las sociedades.

Repárese en que han surgido innumerables teorías que han intentado dar respuesta a estos comportamientos que desarticularon en gran medida los paradigmas tradicionales de la delincuencia convencional, los cuales hacían hincapié en que su origen guardaba relación directa con la pertenencia de aquellas personas a clases sociales baja o a grupos segregados, a la pobreza, entre otros factores.

Ese giro fue muy importante y se debió gracias al aporte fundamental del sociólogo y criminólogo Edwin Sutherland en su obra denominada "El delito de cuello blanco"s, pues fue el primero en hablar de la delincuencia perpetrada por los poderosos. Allí se encargó de refutar las explicaciones biológicas y psicológicas de la criminalidad de las clases bajas, es decir, de los pobres.

Para ello, Sutherland elaboró la teoría de los "contactos diferenciales" desde la cual explicaba que el conjunto de valores a partir de los cuales se expresaba el comportamiento criminal no explicaba su existencia, sino que dependía de los contactos específicos a los que el individuo estaba expuesto, en términos sociales y profesionales.

Debe recordarse que el autor escribió su obra en el año 1939, la cual fue censurada y luego presentada 1949, es decir una década más tarde. Como puede advertirse, este vuelco hacia el estudio del comportamiento de las clases altas y los poderosos no es algo reciente, pues tuvo su origen con la obra del autor mencionado precedentemente, hace ochenta años.

Por lo tanto, la idea de amalgamar algunas de estas posiciones tan disímiles en el tiempo, quizás nos permita aproximarnos a comprender la interrelación que se ha venido dando entre la criminología y la globalización.

De allí, la importancia de la introducción que aquí presentamos.

5 Edwin Sutherland "Los delitos de cuello blanco", traducido por Rosa del Olmo en 1969 para la Colección Genealogía del Poder, (Madrid: Edit. La Piqueta, 1999), 38. 
1.1. EL IMPACTO DE LA GLOBALIZACIÓN EN LA CRIMINOLOGÍA. EL DEBATE EPISTEMOLÓGICO

En primer lugar, para entender de qué trata esto del paso de una criminología crítica focalizada en el estudio del individuo y sus comportamientos hacia una criminología más global, con motivo de la internacionalización del delito, puede explicarse a partir de la denominada ruptura epistemológica por medio de la cual una disciplina científica puede ir mutando con el paso del tiempo. Tal como lo explica el filósofo Gastón Bachelard, ello se produce porque los diferentes actos que se realizan contrastan con lo que él denomina el "mito continuista" del empirismo6.

En términos sencillos, estaremos ante una ruptura epistemológica en aquel momento en el que se produzca una transformación tanto del objeto de estudio, como del proceso de conocimiento utilizado para el análisis de una situación determinada, lo que provocará, sin más, un enfoque distinto y novedoso del estudio de ese objeto, en comparación con el que se venía utilizando y observando.

Antonio García-Pablos de Molina tiene dicho:

"El saber criminológico, es, pues, como todo saber científico, un saber inevitablemente relativo, inseguro, abierto, provisional. En primer lugar, por razón de su objeto.” y agrega a posteriori que “...el propio progreso científico reclama modelos teóricos más sólidos y convincentes, metodológicamente mejor dotados y más operativos desde un punto de vista político criminal... A este superior nivel de exigencias se debe, sin duda, el abandono de las teorías mono-causales de la criminalidad que fascinaron en otro tiempo. Y el claro intento de la moderna doctrina de formular modelos cada vez más complejos e integradores, paliando el déficit empírico que acusaban algunas construcciones tradicionales...”7.

Como puede verse, la posición que asume García-Pablos de Molina en torno al rol protagónico que le cabe a la criminología y su aportación en concreto, convalida de algún modo este quiebre epistemológico al que venimos haciendo referencia.

6 Pedro Karczmarczyk, "La ruptura epistemológica de Bachelard a Balibar y Pêcheux. Estudios de epistemología.", (La Plata: Revista Memoria Académica nº 10, 2013), 30-31.

7 Antonio García-Pablos Molina "La aportación de la criminología" (San Sebastián: Edit. Eguzkilore, Cuaderno del Instituto Vasco de Criminología $\mathrm{N}^{\circ} 3,1989$ ), 79-94. 
Sobre la cuestión, Pedro Karczmarczyk tiene dicho:

“...en la ruptura se produce un desvanecimiento de la evidencia preexistente...Con la ruptura se inaugura un nuevo territorio de investigación, antes vedado, lo que constituye un evento caracterizado por la irreversibilidad. Este mismo par (ruptura y reestructuración) permite dar cuenta de la intemporalidad de la verdad, que también es pensada como un efecto, es decir, en términos de la recurrencia y reflexividad de este mecanismo de ruptura, a esto se denomina propiamente reestructuración"».

En ese punto vale traer a Camilo Bernal Sarmiento, quien explica que la propuesta sería entonces la de ampliar el objeto y estudiar los crímenes corporativos, las matanzas, los desastres medioambientales, los movimientos forzosos de personas (desplazados, etc.), la corrupción, la privatización de las intervenciones armadas, pero desde una perspectiva global e inclusiva 9.

Por lo tanto, en lo que concierne a la denominada criminología global, estaríamos en condiciones de pensarla, quizás, como aquella que provocó la ruptura epistemológica que hemos intentado explicar hasta aquí, pues ha modificado el objeto de estudio criminológico radical focalizado en el sujeto y sus conductas sociales, por el del estudio de los delitos cometidos por los Estados, el crimen organizado y las corporaciones económicas internacionales, entre otras tantas.

1.2. EL ROL DE LA CRIMINOLOGÍA CONTEMPORÁNEA Y EL APORTE DE LA OBRA TRADUCIDA- DE WAYNE MORRISON

Ahora bien, este apartado no puede comenzar sino a partir de las preguntas que Wayne Morrison se hacía en su obra "Criminología, civilización y nuevo

8 Karczmarczyk. "La ruptura..., 30-31.

9 Camilo Bernal Sarmiento, Sebastián Cabezas Chamorro, Alejandro Forero Cuellar, Iñaqui Rivera Beiras e Iván Vidal Tamayo "Un debate epistemológico sobre el daño social, los crímenes internacionales y los delitos de los mercados" (Buenos Aires: Edit. La Ley, Revista de Derecho Penal y Criminología, 2012), 62-63. 
orden mundial" con respecto a que era lo que sucedía con la criminología durante aquellas épocas tan oscuras de la historia contemporánea.

Entre otros cuestionamientos, Morrison se preguntaba:

“¿En dónde estuvo la criminología desde mediados del S. XIX hasta la actualidad mientras los Estados produjeron cientos de crímenes masivos? o ¿Qué función cumplió el discurso de la criminología en la modernidad, en la ejecución de las masacres que se disfrazan como parte del proceso civilizador? "10.

De su lectura puede advertirse la interpelación que le hace a la criminología, preguntándose si es posible enfrentar las atrocidades del "espacio civilizado" mediante un proyecto de criminología crítica global.

En resumidas palabras, Morrison le cuestiona a la criminología que siempre se ocupó de estudiar la criminalidad del "mundo civilizado", integrado por hombres, blancos, libres y propietarios, cuyo poder hegemónico y dominante llevó a que esta disciplina elaborara un "discurso de la seguridad del espacio civilizado", dejando de lado el estudio de los delitos cometidos por los grupos de poder que, a fin de cuentas, eran los que dominaban aquel "mundo civilizado".

Ello provocó la necesidad de entender por qué se había gestado a la criminología como un saber selectivo y discriminador durante la producción de los crímenes en masa (el genocidio armenio, el Holocausto nazi, las atrocidades del fascismo en Italia y de la dictadura franquista en España, la matanza de los opositores políticos en la Unión Soviética, las desapariciones, las torturas y las ejecuciones extrajudiciales de las dictaduras latinoamericanas, etc.).

De tal importancia resultaron estas aportaciones que Luigi Ferrajoli expresó: “...Debemos estar agradecidos a Wayne Morrison y a aquellos que lo han traducido, comentado y han desarrollado sus tesis, por haber promovido el desarrollo de una criminología que asuma como objeto de estudio también a los crímenes globales, y por haber ampliado, por tanto, el campo de las investigaciones criminológicas más allá de los espacios estrechos, subordinados a los poderes

10 Wayne Morrison “Criminología..., 54. 
constituidos: por promover el desarrollo de una "criminología global" que asume como objeto de estudio el delito global"11.

\section{EL "APARTHEID GNOSEOLÓGICO"}

Tales sucesos, dieron lugar a una búsqueda dirigida a identificar las razones que pudieron fundamentar la construcción del denominado "apartheid gnoseológico”, esto es, que la criminología siempre miraba hacía un mismo lugar, aún a sabiendas de las atrocidades que sucedían a nivel mundial.

Algunas de las explicaciones que lo determinaron, pueden identificarse en la obra de Iñaki Rivera Beiras denominada "Delitos de los Estados, de los Mercados y daño social"12, pues allí propone una serie de explicaciones que contribuyen a comprender porque la criminología no tuvo un rol activo en ese aspecto.

Allí sostiene que la primera explicación se remite a la decisión de los criminólogos de concentrarse en los delitos ordinarios obviando analizar la criminalidad masiva, ya que fue recién a partir del movimiento internacional de los derechos humanos que los académicos empezaron a preguntarse por estos delitos. La segunda explicación se vincula con la primera, ya que las definiciones del derecho penal internacional empezaron a surgir con aquel movimiento de los derechos humanos, que derivó en que los criminólogos se ocuparan de analizar esos crímenes, y ya no únicamente aquellos previstos en las legislaciones internas. La tercera tiene que ver con la imposibilidad metodológica -que supone una contradicción interna- del hecho de investigar las violaciones cometidas por los mismos Estados que deben garantizar la prevención y el castigo de delitos. La cuarta, se encuentra íntimamente relacionada con la anterior, pues se vincula con la dificultad de analizar las causas de los delitos de genocidio y graves violaciones a los derechos humanos. La quinta, guarda relación con aquella

11 Luigi Ferrajoli, “Criminología, crímenes globales y derecho penal: el debate epistemológico en la criminología contemporánea” (Universidad de Barcelona: Revista Crítica Penal y Poder $\mathrm{n}^{\circ} 4,2013$ ), 224.

12 Iñaki Rivera Beiras (coord.) "Delitos de los Estados, de los Mercados y daño social” (Barcelona: Edit. Anthropos, 2014). 
defensa social que fomentaron los Estados con discursos que legitimaban una aplicación selectiva de la ley que nunca alcanzó a los poderosos ni a las acciones del propio Estado. La sexta explicación se vincula sobre el estado de negación mental de las personas en relación con la violencia colectiva -según Cohen-, pero esta vez centrándose en los agentes principales de esta disciplina ${ }^{13}$. La séptima tiene que ver con la posición etnocéntrica, occidental y dominante de la criminología, que ha provocado que el objeto de estudio se posicione dentro de los límites del denominado "mundo civilizado". Por último, la octava explicación se vincula con la connivencia existente entre los poderes internacionales de los Estados, que impedía las posibilidades de denuncia y control de sus abusos.

\subsection{LA REPERCUSIÓN DE LA GLOBALIZACIÓN. EL DAÑO SOCIAL}

Como es sabido, la opinión de la comunidad internacional es pacífica en cuanto a que la revolución de las nuevas tecnologías de la información y las comunicaciones han tenido un papel protagónico en la nueva reestructuración geopolítica mundial, sumado a las aperturas económicas de intercambio de mercancías, bienes y servicios y la liberación de los mercados de capitales internacionales, los cuales son todos elementos que componen el fenómeno de la globalización, cristalizado fundamentalmente en la conexión en tiempo real que existe a nivel mundial.

En contrapartida, y desde un enfoque más individual, apunta Carlos Elbert:

"El cambio global arrastró consigo también los valores y pautas precedentes de comportamiento social e interpretación de la realidad. Como consecuencia, una anomia masiva (...) recorre buena parte de la humanidad, alterando las reglas de juego que la modernidad había establecido durante tanto tiempo... Sucede que estamos frente al hombre global, que dejó de ser ciudadano, y hoy sólo tiene relevancia mediante su poder adquisitivo, su capacidad de consumo y, eventualmente, su protagonismo público. El contexto del hombre global tiene,

13 Camilo Bernal Sarmiento..., "Un debate epistemológico, 56. 
necesariamente, un devenir caótico, sin valores generales, cultura ni recursos afectivos como orientación..."14.

Todo ello, en gran medida genera un daño social inconmensurable, puesto que no sólo se trata de establecer estadísticamente cuantos delitos tipificados en el orden nacional e internacional se han cometido, o bien las consecuencias que han generado, pues resultaría ilusorio pensarlo de ese modo. El problema radica en que la multiplicidad de conductas que generan aquellos daños irreversibles impacta casi mortalmente en las sociedades, y no siempre son ilícitas.

En palabras de Paddy Hillvard el término daño social supone “...una amplia gama de eventos y condiciones que afectan a las personas durante el curso vital" 15 , tales como los daños físicos (muerte prematura, exposición a diferentes contaminantes del medio ambientes, falta de alimentación, etc.), los daños económicos y financieros (falta de empleo, venta fraudulenta de pensiones e hipotecas, etc), los daños emocionales y psicológicos (vinculados a los daños mencionados) y los daños de seguridad cultural (imposibilidad de acceso a recursos culturales, intelectuales e informativos).

En ese sentido, debe señalarse que la tendencia es que los daños sociales se encuentran identificados como una nueva noción de crimen globalizado y, en ese marco, es que tal como sostienen quienes dominan esta materia, deben diferenciarse entonces entre los crímenes globales o de sistema y crímenes de mercado.

Sucede que la agenda pública de los Estados se encuentra limitada por los intereses políticos y económicos de los grupos de poder -mediante el lobby, la corrupción, las corporaciones y la competencia desleal-, quienes únicamente miden los acontecimientos, en términos de beneficios, y a como dé lugar. Ello, se traduce muchas veces en políticas antidemocráticas que perjudican a los pueblos causando graves daños sociales y favorecen únicamente a los poderosos.

14 Carlos Elbert "Manual básico de criminología” (Buenos Aires: Edit. Eudeba, cuarta edición ampliada y actualizada, 2007), 197. Con cita de Massimo Pavarini “Control y dominación” (México: Edit. Siglo XXI, 1983), 175-176.

15 Paddy Hillyard y Steve Tombs ¿Más allá de la criminología?, traducida por Khatarina Vogels y Alejandro Forero Cuellar (Barcelona: Revista Crítica Penal y Poder nº 4, 2013), 184. 
En esa inteligencia, sostiene Luigi Ferrajoli que “...los poderes económicos y financieros se han desarrollado como poderes sin límites, sin reglas y salvajes, en grado de imponer sus propias reglas y sus intereses a la política...”. En punto a los crímenes globales o de sistemas señala que serán aquellos que “...no consisten en unos comportamientos determinados, sino un conjunto de actividades políticas y/o económicas, llevadas a cabo por una pluralidad indeterminada y a la vez indeterminable de sujeto... Estos crímenes, de hecho, no son configurables como delitos..."16.

La conjunción de tales elementos penetra en lo más profundo de las sociedades, sobre todo en aquellas más necesitadas, en las cuales impera la pobreza, el hambre, la discriminación, la falta de atención sanitaria, etc. Todo ello sumado a las consecuencias naturales que se derivan del calentamiento global y a las provocadas por los seres humanos a nivel mundial, tales como los delitos ambientales, el tráfico de armas, la trata de personas, la explotación sexual y laboral, entre otras.

En punto a ello, cabe transpolar para cerrar esta cuestión la explicación que Gabriel Anitua realiza en su obra "Historia de los pensamientos criminológicos" que tituló "El actuarialismo. La gestión y evitación de riesgos en la sociedad excluyente global" al referir:

"La actual respuesta que dan conjuntamente las sociedades de consumistas y los nuevos expertos que crean y manejan necesidades de consumo parece estar fundamentada en la precariedad, en la incertidumbre y en los riesgos. Tales riesgos llegan finalmente a afectar a las propias estructuras económica y política... Pareciera que ese sospechoso que tenía en mente al iniciar este libro se me ha muerto con la mencionada precarización de la vida. Ni las empresas comerciales ni las estatales parecen asegurar a los individuos un "rol”, un trabajo o actitud, que pueda mantenerse para siempre. Las estructuras parecen ser menos longevas que los mismos individuos, los que a su vez aumentan sus temores y sus respuestas racionales dentro de la irracionalidad" ${ }^{17}$.

16 Luigi Ferrajoli, “Criminología..., 90.

17 Gabriel Ignacio Anitua "Historia de los pensamientos criminológicos" (Buenos Aires: Edit. del Puerto, primera edición, segunda reimpresión, 2010), 521-522. 


\section{LA CRIMINOLOGÍA CRÍTICA}

Como es sabido, la criminología crítica o radical nace en la década de los años 70, inspirada en los postulados de los teóricos de la Escuela de Frankfurt, que reunió a personalidades del mundo intelectual, incluyendo filósofos, sociólogos, politólogos, psicólogos e investigadores de distintas ciencias sociales, tales como Theodor Wiesengrund-Adorno, Max Horkheimer, Erich Fromm, Walter Benjamin, Leo Loewenthal y Herbert Marcouse, entre otros tantos.

Su aporte más trascedente considerando el contexto sociopolítico de la época, fue el de haber realizado -entre las décadas de 1920 y 1930- una interpretación social de conjunto, es decir, a través del estudio y la investigación interdisciplinaria, con la intervención de distintas áreas sociales y culturales.

Carlos Elbert expresó con relación a ello:

"Existen pocos intentos tan serios de establecer, desde un tratamiento científico del marxismo, la relación que media entre las ideas y la base social. Muchos teóricos ubican el germen de la criminología crítica posterior, la de raíz marxista, en esta búsqueda original, anterior a 1945 (...) Era un grupo en guerra con el mundo burgués y sus valores, pero que se mantuvo a prudencial distancia de competencias de prestigio con otros institutos o centros de investigación, cuidando a sus miembros de una excesiva exposición política. (...) El instituto fue un centro único, por tener como objeto permanente de análisis y estudio los temas de la ideología y la crítica ideológica, o sea la investigación de las relaciones entre las ideas y la base social"18.

Retomando el origen de la criminología crítica -durante la década del 70' -, debe señalarse que quienes participaban de este movimiento caracterizado por el estudio multidisciplinario de las conductas sociales, no respondían a un esquema consensuado o uniforme, sino que más bien funcionaba como algo heterogéneo. No obstante, desarrollaron su trabajo a partir de la teoría del conflicto en su adaptación marxista, pues sostenían que de ningún modo podía estudiarse el crimen en forma aislada porque formaba parte del contexto social.

18 Carlos Elbert “Manual..., 141 y 145-146. 
Puede decirse entonces que los críticos se propusieron dejar de lado las interpretaciones individualistas del delito, como la biología, la genética y la psicología, entre otras, para recuperar los postulados de la teoría y la filosofía crítica con el objeto de franquear los límites epistemológicos del estudio de la criminalidad tradicional, positivista y dominante, e ir en buscar una nueva concepción del delito y comprensión del funcionamiento de las agencias de control.

Entre sus expositores se destacan los criminólogos ingleses (Ian Taylor, Paul Walton, Jock Young, Stan Cohen y Laurie Taylor) y los italianos (Alessandro Baratta, Dario Melossi y Massimo Pavarini), a los cuales se fueron sumando referentes como Roberto Bergalli y Lola Aniyar de Castro en Latinoamérica.

Tiene dicho Alessandro Baratta:

"La criminología crítica, se ha dirigido sobre todo al proceso de criminalización, individualizando en él uno de los mayores nudos teóricos y prácticos de las relaciones sociales de desigualdad propias de la sociedad capitalista, y persiguiendo, como uno de sus objetivos principales, extender de un modo riguroso la crítica del derecho desigual al campo del derecho penal. Elaborar una teoría materialista (económico-política) de la desviación, de los comportamientos socialmente negativos y de la criminalización, y trazar las líneas de una política criminal alternativa, de una política de las clases subalternas en el sector de la desviación...”19.

Sobre la cuestión, explica Gabriel Anitua:

"Esa interdisciplinaridad se verificaría en el "barattiano" modelo integrado de ciencia del derecho penal, como método de control "interno" de la justicia penal y también como discurso científico más abierto de control "externo". Para esa última tarea era fundamental atender el desarrollo epistemológico de una "sociología del control penal" pues no sólo para el límite y la denuncia sino para la construcción de respuestas sociales coordinadas y coherentes -adecuadas a la

19 Alessandro Baratta "Criminología Critica y crítica al Derecho Penal" (México: Edit. Siglo XXI, 1984), 209. 
complejidad de la realidad- sería necesario considerar, simultáneamente, el mayor número de variables y utilizar las más variadas herramientas”20.

Sentado ello, debe señalarse que la incursión de la criminología crítica fue reconocida por sus seguidores como un verdadero cambio de paradigma, pues modificó radicalmente la disciplina como estaba concebida hasta entonces y por las razones que hemos venido exponiendo, motivo por el cual no debe soslayarse que su contribución se encuentra más vigente que nunca, y de allí que nos encontremos analizando si la criminología contemporánea ha sufrido cambios con el fenómeno de la globalización.

\subsection{UNA APROXIMACIÓN A LA CRIMINOLOGÍA GLOBAL}

Ahora bien, se ha intentado realizar un modesto abordaje que nos permita comprender las razones por las cuales esta disciplina -la criminología críticaha ido mutando con el tiempo, creando un escenario de discusión en términos epistemológicos que no parecería tener fin, pues, como es sabido, la realidad es una fuente de estudio inagotable.

En ese marco, entonces, es la criminología la que debe pensar y elaborar nuevas propuestas teóricas y prácticas de cara a la problemática que la globalización le ha planteado a la humanidad.

En esa idea, debemos retrotraernos nuevamente a Edwin Sutherland, pues como ya hemos mencionado al inicio de este trabajo, fue un adelantado al proponer como objeto de estudio, la delincuencia de los poderosos, de las clases altas. No debe soslayarse que ese giro criminológico tuvo su génesis en una etapa de post crisis económica -la Gran Depresión de 1929-. Recuérdese que, fue la más devastadora caída de los mercados de valores en la Bolsa de los Estados Unidos de América del siglo pasado.

En efecto, el concepto de criminalidad de cuello blanco como ya mencionamos con anterioridad se originó a partir de las teorías de la asociación o

20 Gabriel Ignacio Anitua "Historia..., 462. 
contactos diferenciales y de las subculturas criminales que se desarrollaron en la Escuela de Chicago, cuya particularidad consistía en el desplazamiento del saber criminológico individual hacia una perspectiva global de la sociedad.

Aquel término acuñado por Sutherland despertó la atención social por aquellos tiempos, dado el contexto en el que la desarrollo, pues corrió un velo hasta entonces prohibido al señalar a las clases sociales altas y a los poderosos como protagonistas en el fenómeno de la delincuencia.

Ilustra aún más su posición cuando explica:

"Lo significativo del delito de "cuello blanco" es que no está asociado con la pobreza, o con patologías sociales y personales que acompañan la pobreza. Si se puede mostrar que los delitos de "cuello blanco" son frecuentes, se considerará inválida una teoría general que muestre que el delito se debe a la pobreza y a sus patologías relacionadas. (...) El costo financiero del delito de "cuello blanco" es probablemente varias veces superior al costo financiero de todos los delitos que se acostumbra a considerar como el "problema delictivo"21.

Su investigación dejar ver que el delito de "cuello blanco" es un crimen organizado y señala:

“...los delitos de las corporaciones han mostrado que éstas han cometido delitos contra una o más de las siguientes clases de víctimas: consumidores, competidores, accionistas y otros inversores, inventores y empleados, así como contra el Estado en la forma de fraude a impuestos y soborno a funcionarios públicos. Estos delitos no son violaciones discretas ni desapercibidas de reglamentos técnicos. Son actos deliberados y tienen una relativa unidad consistente" ${ }^{22}$.

Por su parte, la destacada criminóloga Lolita Aniyar de Castro tiene dicho que el aspecto medular de este delito es su carácter clasista, y allí es en donde

21 Edwin Sutherland "Los delitos..., 261.

22 Ibíd. 
radica su importancia, pues provoca una revolución en el objeto de la criminología tradicional ${ }^{23}$.

Así las cosas, puede afirmarse entonces que fueron aquellos cuestionamientos de Sutherland los que sentaron las bases que permitieron ampliar y modificar el objeto de estudio de la criminología como estaba concebida hasta entonces, y son ahora también el antecedente y el fundamento que nos permite -tomándolo como ejemplo- repensar nuevamente la criminología, en este contexto de globalización.

\section{EL ESCEPTICISMO CRIMINOLÓGICO}

A esta altura, no podría desconocerse que desde antaño se ha cuestionado que la criminología sea una ciencia, pues si bien se ha ido consolidando en el tiempo entre otras razones por el rasgo interdisciplinario de sus investigaciones, lo cierto es que también se la denomina parte de un ámbito de estudio sin objeto definido en el que, al converger tantas especialidades, se torna heterogénea e indeterminada.

En este punto, nos recuerda Carlos Elbert:

"La criminología fue considerada, una Ciencia con mayúscula, que se creía definitivamente establecida en el marco epistemológico. Sin embargo, la confluencia de saberes diversos en su producción ha complicado en extremo la búsqueda de un objeto y un método propios, razón por la cual la criminología podría ser definida como ciencia...” y agrega que Massimo Pavarini explicó irónicamente esta situación diciendo que “...la criminología no es una ciencia autónoma en la medida en que no tiene un objeto definido, no procede en base a la aceptación de paradigmas comunes y aún menos con un mismo método... En suma, una cómoda sombrilla cuya sombra se resguarda en personas de distinta lengua, a veces incapaces de entenderse entre sí, pero todas igualmente preocupadas por

23 Lolita Aniyar de Castro "La realidad contra los mitos: reflexiones críticas en la criminología". (Maracaibo: Edit. Universidad del Zulia, 1982), 155. 
el desorden reinante en la sociedad, aunque cada una de ellas lo atribuye a razones distintas"24.

Agrega también Elbert:

“...Otra postura agnóstica original es la que plantea Zaffaroni, sosteniendo una visión de la historia de la criminología de carácter global, negando que arranque en Lombroso, sino con el manual para inquisidores, Malleus Maleficarum (martillo de las brujas), del siglo XV. Con base en esa obra afirma que: En criminología todos los discursos están vivos, es decir, no estamos recorriendo un zoológico de animales vivos de todas las épocas. Ningún discurso muere, son los árboles, pero árboles que lo que más puede pasar es que cambien el follaje, pero siguen presentes, son todos contemporáneos" 25.

Sobre la cuestión, concluye Elbert que, si bien la criminología podría no ser considerada como una ciencia porque no poseía métodos propios ni un objeto establecido con claridad y consenso, lo cierto es que no puede menospreciársela porque no es menos seria que otras, y también puede ser materia de controversia epistemológica.

Como puede advertirse a lo largo de este trabajo, la criminología ha despertado innumerables cuestionamientos, hasta el punto de haber sido negada como ciencia, lo que no significa, empero, que deba ser subestimada como bien señala Elbert, pues “...la criminología está legitimada como disciplina científica e interdisciplinaria, en tanto, aún sin disponer de un objeto unívoco ni de un único método, puede tratar .legítimamente- temas relativos al crimen y al control social con coherencia científica, valiéndose de objetos y métodos de distintas disciplinas" ${ }^{26}$.

24 Carlos Elbert “Manual..., 197.

25 Ibid.

26 Ibid. 


\section{PALABRAS FINALES}

Como se ha visto, en este trabajo hemos intentado abordar algunas de las cuestiones que han ido impactando en la evolución de la criminología contemporánea. Ello, asumiendo que la "aldea global” que proponía MacLuhan se ha consolidado en todas las esferas de la humanidad. A tal punto es así, que, desde este ámbito criminológico en el que se estudian los temas relativos al delincuente, al crimen y al control social, no deben detenerse los esfuerzos que nos permitan ir perfeccionado esta disciplina.

Más allá de que en sus inicios se haya presentado como una ciencia, cuyo objeto de estudio y métodos de investigación aparecían como firmemente establecidos, lo cierto es que quienes la integraban tampoco estuvieron muy de acuerdo en ese aspecto, sobre todo por sus rasgos tan cambiantes, aunque sí había consenso en que no debía ser subestimada, pues la seriedad de aquellas otras disciplinas involucradas en esta ciencia, han colocado a la criminología en un lugar de constante discusión epistemológica.

En ese marco, podríamos decir entonces que, para encarar el estudio de una criminología global, debería tenerse en consideración que esta disciplina en sus orígenes respondía a una posición dominante que actuó en consecuencia.

Una mirada en retrospectiva revela que con el transcurso del tiempo la criminología no ha tenido más alternativa que reutilizar los instrumentos aprendidos para ir modificando sobre la marcha sus objetos de estudio y procesos de investigación, y ello gracias a la claridad que aportaron trabajos como los de Wayne Morrison que permitieron pensarla desde otra perspectiva, siendo así como fue encontrando el camino para adaptarse al impacto que el fenómeno de la globalización -desde todos los enfoques, pero más que nada en términos de criminalidad- provoca a nivel mundial.

Por último, cualquiera sea la contribución científica que realice cada una de las disciplinas que integran la criminología de estos tiempos, impactará constructivamente y permitirá, sin lugar a duda, por encontrarse en constante movimiento, ampliar los horizontes del conocimiento en esta materia. 
Por ello, vayan estas líneas como aporte al debate.

\section{REFERENCIAS BIBLIOGRÁFICAS}

Anitua, Gabriel Ignacio. Historia de los pensamientos criminológicos. Buenos Aires: Edit. del Puerto, 2010.

Aniyar de Castro, Lolita. La realidad contra los mitos: reflexiones críticas en la criminología. Maracaibo: Universidad del Zulia, 1982.

Baratta, Alessandro. Criminología Critica y crítica al Derecho Penal. México: Siglo XXI .2009.

Baumann, Zygmun. La globalización. Consecuencias humanas. Buenos Aires: Edición del Fondo de Cultura Económica, 1999.

Bernal Sarmiento, Camilo; Sebastián Cabezas Chamorro; Iñaqui Rivera Beiras e Iván Vidal Tamayo. Más allá de la Criminología. Un debate epistemológico sobre el daño social, los crímenes internacionales y los delitos de los mercados. Buenos Aires: La Ley, 2012.

Elbert, Carlos. Manual básico de criminología. Cuarta edición ampliada y actualizada. Buenos Aires: Eudeba, 2007.

Ferrajoli, Luigi. "Criminología, crímenes globales y derecho penal: el debate epistemológico en la criminología contemporánea”. Revista Crítica Penal y Poder 4 (2013): 1-11.

García-Pablos Molina, Antonio. "La aportación de la criminología”. Cuadernos del Instituto Vasco de Criminología 3 (1989): 79-94.

Hillyard, Paddy y Steve Tombs. ¿Más allá de la criminología? Revista Crítica Penal y Poder 4 (2013): 175-196.

Karczmarczyk, Pedro. "La ruptura epistemológica de Bachelard a Balibar y Pêcheux. Estudios de epistemología”. Revista Memoria Académica 10 (2013): 9-33.

Macluhan, Marshall y B. R. Powells. La Aldea Global. Barcelona: Gedisa, 1995.

Morrison, Wayne. Criminología, civilización y nuevo orden mundial. Traducida y editada por Camilo Bernal Sarmiento, Sebastián Cabezas Chamorro, Alejandro Forero Cuellar, Iñaki Rivera Beiras, Iván Vidal Tamayo y Fidel Amat. Barcelona: Anthropos, 2012.

Rivera Beiras, Iñaki (Coord.). Delitos de los Estados, de los Mercados y daño social”. Barcelona: Anthropos, 2014.

Rivera Beiras, Iñaki. Recorridos y Posibles Formas de la Penalidad. Barcelona: Anthropos, 2005 . 
Sutherland, Edwin. Los delitos de cuello blanco. Traducido por Rosa del Olmo en 1969 para la Colección Genealogía del Poder. Madrid: La Piqueta, 1999.

Tocora López, Luis Fernando. Política criminal global en América Latina. Mitos y realidades. Buenos Aires: Eudeba, 2015.

José Antonio Michilini

Área de Derecho Penal

Universidad de Buenos Aires (Argentina)

Facultad de Derecho

jamichilini@derecho.uba.ar

https://orcid.org/oooo-0003-1619-5685

Nicolás Pablo Segura

Área de Derecho Penal

Universidad de Buenos Aires (Argentina)

Facultad de Derecho

nsegura@derecho.uba.ar

https://orcid.org/oooo-0003-1101-7775 
